\title{
Chainat: A Case Study in Occupational Health and Safety Promotion for Farmers
}

\author{
Sara ARPHORN ${ }^{1 *}$, Richard BROOKS ${ }^{2}$ and Panupun PERMSIRIVANICH ${ }^{3}$
}

\author{
${ }^{1}$ Mahidol University, Department of Occupational Health and Safety, Bangkok, Thailand \\ ${ }^{2}$ Duke University School of Medicine, Durham, North Carolina, USA \\ ${ }^{3}$ Public Health Care Unit, Subphaya District, Chainat Province, Thailand
}

Received August 31, 2005 and accepted November 25, 2005

\begin{abstract}
The high rates of occupationally related injuries, accidents, and deaths in rural Thailand are of particular concern to public health officials, as well as the residents and workers living in these areas. In response to specific concerns raised by local residents and local health officials in Chainat Province, Thailand, the Work Improvement in Neighborhood Development (WIND) programme was introduced and implemented by means of the local Primary Care Unit (PCU). The objective was to improve farmers' knowledge of methods to improve occupational safety and to reduce the occurrence of occupationally related injuries, accidents, and deaths in the area. Local farmers, public health officers, and health volunteers from the PCU played a primary role in the programme, serving as trainers in the initial training of trainer session. Major activities included visiting a local farm to carry out a check-list improvement activity and active discussion among participants about potential improvements. Following the implementation of WIND in Chainat, a number of significant improvements in work conditions were noted, including construction of resting corners, plans to build toilets in the fields, improved knowledge about the dangers of chemical fertilizers and pesticides, and increased use of personal protective equipment. Furthermore, participants began making organic fertilizer and had independently developed an organic anti-snail pesticide. This integrative approach, achieved by including many different members of the community, in combination with government support and diligent follow-up, has proved to be particularly successful.
\end{abstract}

Key words: WIND, Occupational health and safety for farmers, Integrative approach

\section{Introduction}

Industrialization has accelerated sharply in Thailand throughout the last decade. In 2004, the labor force consisted of a total of 35.7 million workers ${ }^{1}$. Official statistics indicate that 38 percent of the labor force is still employed in the agricultural sector. In addition to the usual problems of poor working postures, long work hours, and exposure to extreme temperatures, the rapid expansion of the agricultural sector has resulted in farmers being exposed to other serious problems as well. Intense chemical use is currently the preferred method for increasing productivity, and machines play a larger role in the working life of Thai farmers than in the past, resulting in increase in occupationally related

*To whom correspondence should be addressed. accidents, illnesses, and deaths. Data from the Ministry of Labor indicate that there were 1,552 cases of occupationally related accidents in the agricultural sector in 2002 alone $^{2}$.

Preventive strategies are considered to be the most effective way to ameliorate many of the occupational safety hazards that plague so many Thai workers. The Work Improvement in Neighborhood Development (WIND) programme provides participatory and action-oriented training for farmers, designed to bring about rapid and sustainable improvements in home and workplace health and safety ${ }^{3,4}$. To ensure sustainability, as well as relevance, WIND is reliant on and responsive to farmers' own initiatives, knowledge, and resources $^{5}$. Sustainability of the programme is further improved by training local officials as trainers ("trainingof-trainers," TOT), thus enabling them to conduct WIND workshops on their own. One-day WIND training courses 
comprising house and field visits with action-checklist exercises and group discussions are conducted by local community trainers who had previously been trained in TOT courses. Local WIND trainers conduct the training by demonstrating good, locally-derived examples, and by enabling participants to assess their own situations and make decisions about which changes will be most beneficial for them. Subsequent follow-up activities, in which a local team analyzes the farmers' successes in implementing chosen improvements, provide further motivation and encouragement to participants.

Attempts have been made to develop a variety of models for the implementation of WIND, dependant upon the needs of the participating community. One particularly successful approach has been to use an interdepartmental model. This approach strengthens the WIND supportive network by linking local personnel from the Ministries of Public Health, Interior, Agriculture, Education and Labor. Such networks further ensure the continuation of the WIND programme as a successful and practical measure to improve the safety and health of Thai farmers.

The current case study examines a new approach used to implement WIND in Muu 5, Had-Asa Subdistrict, Subphaya District, Chainat Province, an area in which the primary source of income is rice farming. Prior to implementation of WIND here, there had been several anecdotal reports of occupational injuries, particularly pesticide poisonings. Other incentives for introducing the WIND methodology in the region included the growing realization among local citizens of the negative impact of chemical pesticide and fertilizer use on the environment. For instance, due to the use of such chemicals, people were not able to eat fish caught in the flooded rice fields. Furthermore, from an economic standpoint, farmers were keen to find a cheaper alternative to expensive chemical fertilizers.

\section{Methods}

An initial WIND TOT programme was implemented in Chainat on November 4-5, 2003 and 32 participants joined or attended. Topics emphasized in the training program included basic knowledge about the hazards of various chemicals including pesticides, the importance of using personal protective equipment (PPE) when dealing with dangerous machinery and chemicals, and the benefits and potential uses of organic fertilizers. Additionally, the need for regular, routine health examination to screen for potential exposure to agrochemicals was also discussed. On January 6,2004 , this group of trainers conducted a WIND workshop for approximately 40 local farmers.

The workshop took place in the community's Primary Care Unit (PCU), an office whose primary mission is "to care for the local people from conception until death." Its main priority areas include disease prevention, home visits, health monitoring, and monetary support for health initiatives. Additionally, however, the PCU also provides other services, such as a food safety program, health provisions for local students, and maternal and child health care, including various birth control options. The PCU employs four full-time professionals-two nurses and two public health officers. Additionally, a physician, a dentist and a pharmacist spend one full day per week at the PCU and also provide services when the permanent staff is overwhelmed. The PCU is responsible for approximately 4,200 people dispersed among 4 villages in 3 tambols. Each tambol has a public health station, which is supported and organized by the staff at the PCU.

Of the 32 persons trained as trainers at the initial WIND TOT workshop, 12 also act as health volunteers at the PCU. In their role at the PCU, these volunteers act as supporting staff for the permanent staff, helping to promote health among local residents living in the four villages. As WIND trainers, the volunteers often gave morale support to farmers and helped the farmers conduct projects that they were unable to complete on their own.

\section{Results and Discussion}

On March 3, 2004, the authors returned to Chainat to determine what changes had been carried out as a result of the WIND training program. Several new programs had been developed in coordination with the PCU and as part of a program supported by the Electricity Generating Authority of Thailand, EGAT, to encourage farmers to start using organic fertilizers. Whereas some farmers in the area had been found to be using up to 15 different chemical pesticides on their crops prior to the WIND workshop, this number was reduced drastically as farmers began making and using their own organic fertilizer from leftover rice, chicken manure, and biologically active microorganisms donated by EGAT. Furthermore, in the process of demonstrating how the farmers make their fertilizer, it was noted that they were now using personal protective equipment, such as rubber boots, gloves, long pants, and simple masks.

In an effort to further reduce the use of potentially dangerous chemicals, one of the farmers had developed a non-toxic anti-snail pesticide made from ground-up snails and locally grown herbs. The concoction was mixed, stored for several days, and then poured into the rice fields at the source of water inflow, thus dispersing the organic pesticide in all the fields without the farmers having to spend time or making an effort for spraying. The farmers claimed that the pesticide prevented the snails from eating the rice, eventually resulting in the snails dying from starvation.

Another concrete example of the improvements made as a result of WIND was the construction of resting corners in 
the rice fields of several farmers. Built of bamboo, these cost-efficient and sturdy shelters provided shade and a comfortable spot for the farmers to take needed breaks in the course of carrying out their daily duties. In Thailand's infamous heat and humidity, dehydration and heat stroke are common problems. Several farmers also discussed their plans to build bathrooms in their rice fields, which will lead to improved health and sanitation.

An important contributor to the success of WIND in this province was the integrative approach of using health volunteers at the PCU as some of the WIND trainers. As health volunteers, these people were already familiar to the local farmers and already had tasks that involved traveling to the different villages, talking with the residents, and encouraging them to engage in healthy behaviors. Consequently, it was a relatively simple task to include the principles of WIND among the topics that the volunteers discussed with the residents. WIND led to a number of significant improvements in work conditions from farmer's initiative, therefore it indicated that it was useful and practical tool for better farmer's working conditions in Chainat province.

Some of the inherent qualities of Thai culture also facilitated the success of WIND in this province. On an almost daily basis, many of the local farmers gather together in their village's meeting spot to mingle, chat, and visit with neighbors. When farmers began to initiate projects after the implementation of WIND, these frequent gatherings naturally led to a forum for the exchange of ideas for potential projects. Here residents could discuss what they had done so far, what they were planning on doing, what had worked, what had failed, and the various reasons for their successes and failures. In this way, successful and feasible projects could be passed along to others without those farmer as having to repeat the same mistakes over and over again. Ultimately, the principles of WIND were improved and made relevant to the community at hand.

The creation of such an integrated and widespread network in the Chainat community increases the likelihood that the WIND program will be a sustainable one. In using PCU health volunteers as WIND trainers, WIND has been given a physical organizational center that already has a successful history. Furthermore, by incorporating WIND principles into the teachings of the health volunteers, WIND is given validity and support from a group of people already respected and trusted in the community. Sustainability will be further improved by the idea of a local teacher, who has contacted community officials and asked to be allowed to incorporate WIND into her students' curriculum. If such creative efforts are continued, WIND will quickly become less of a structured programme of principles and ideas and more of a way of living one's life that is second-nature and is passed on to future generations.

\section{Conclusion}

The implementation of the participatory WIND programme led to concrete improvements in the daily work life of farmers and that the usefulness of providing adequate support through training and follow-up was demonstrated. Major activities included visiting a local farm to carry out a check-list improvement activity and active discussion among participants about potential improvements. This integrative approach, achieved by including many different members of the community, in combination with government support and diligent follow-up has proved to be particularly successful in occupational health and safety promotion for farmers by WIND.

\section{References}

1) National Statistics Office (2004) The employment and unemployment situation in whole kingdom 2003-2004. Available at: http://www.labour.go.th/yearbook/file/3.1.pdf (Accessed October 3, 2005).

2) Social Security Office, Ministry of Labour (2000) Annual Report 2003. Social Security Office Print, Nonthaburi.

3) That TK, Kawakami T (2002) Work improvement in neighborhood development: training programm on safety, health and working conditions in agriculture. V, Center for Occupational Health and Environment, Can Tho, Vietnam.

4) Arphorn S, Chaikittiporn C (2004) Work improvement in neighborhood development : training manual for occupational safety, health and working conditions. V, Suksa Printing, Bangkok.

5) Kawakami T, Kogi K (2001) Action-oriented support for occupational safety and health programs in some developing countries in Asia. Int J Occup Saf Ergon 7, 421-34. 